\title{
COMMUNITY ENTREPRENEURSHIP: A FRAMEWORK FOR SOCIAL CHANGE LEADERSHIP
}

\author{
John W. Selsky* \\ University of Otago \\ Anthony E. Smith \\ Lightstone Foundation, WV
}

\begin{abstract}
This article describes a leadership approach to social change that takes into account actors' differing interests, strategic alliances, and events in a dynamic, interorganizational community setting. The leadership and development concepts are drawn from two interwoven action research projects that took place in the Philadelphia area in the mid-1980s. As reflective practitioners, the authors developed and applied a new framework for proactive leadership to achieve social change.
\end{abstract}

The objectives of this article are to: (1) characterize the special requirements for practicing leadership in community-based, social change settings; (2) identify a distinctive kind of leadership, called community entrepreneurship, which is appropriate to such settings; and (3) draw implications for leadership theory and for practice in similar settings.

Community-based social change settings are highly dynamic and complex. They are characterized by diverse interests, temporary and fluid alliances, and fast-paced and equivocal events that confound traditional leadership concepts. By reflecting on our own overlapping community-based experiences, we strive to improve our understanding about how community-based leaders practice social change. We call this practice community entrepreneurship.

* Direct all correspondence to: Dr. John W. Selsky, Department of Management. University of Otago, P.O. Box 56, Dunedin, New Zealand.

Leadership Quarterly, 5(3/4), 277-296.

Copyright ${ }^{\circ} 1994$ by JAI Press Inc.

All rights of reproduction in any form reserved.

ISSN: 1048-9843 
Thus, we believe that community entrepreneurs (CEs) represent a special kind of leader. In addition to being leaders of organizations in their own right, community entrepreneurs play their most critical role in developing the collective capacities of organizations sharing interests in one or more community issues. That CEs play a "game" of strategic action at two levels, organizational and community, makes their practice distinctive and calls for a new appreciation of their role. While leaders in all organizations need to adapt to and enact environments, CEs frequently must do so in the absence or rejection of bureaucratic structures and institutionalized norms for organizational behavior.

Consequently, we make the case that CEs must demonstrate three qualities in concert: (1) an ability to envision and articulate a multiframe perspective; (2) an entrepreneurial orientation in brokering commitments, mobilizing resources, and managing events; and (3) a reflectiveness in their practicc, which enables them to learn from, adapt to, and enact a changing social landscape. These three qualities have been discussed in terms of intraorganizational leadership (e.g., Bolman \& Deal, 1991). This article extends this line of thinking to interorganizational, community-based contexts, where structures and norms are much weaker and need to be constructed (Brown, 1986; McCann, 1983).

The method that we use is empirically grounded and interpretive. Each author was the executive director of a small nonprofit organization in the Philadelphia metropolitan area during the mid and late 1980s. As we compared our experiences in trying to foster social change, we gained important insights about the requirements for community leadership. Hence, this research was guided by several questions: What did community entrepreneurship mean to us and for us? How did we enact it and experience it subjectively and intersubjectively? What lessons can we offer to practitioners in similar situations? And what new insights can be gained for leadership theory? The article adds to our understanding of leadership by demonstrating the importance of each of the three qualities noted above in community-based, social change settings.

\section{TURBULENT SOCIAL ENVIRONMENTS AND COMMUNITY DEVELOPMENT}

Since the early 1980 s, many community-based nonprofit organizations have experienced intense and increasingly uncertain changes in their operating environments. Competitive pressures for funding, swecping political and cconomic changes at the national and state levels, and shifting public attention from issue to issue have created great ambiguity in the "ground rules" and in the nature of the "game" played by nonprofits. For example, the "new right" ideological forces that resulted in the 19811982 Reagan budget cuts to the social service sector were virtually beyond the control of any single social service organization, but seriously affected most of them.

The problem facing nonprofit managers in this scenario has two aspects. First, the ground rules for managing and strategizing are uncertain and shifting in ways that are unfamiliar in the experience of leaders of the affected organizations. This is a problem of turbulence. Second, the locus of the problem lies not with any individual organization but in the structural and normative relationships among a large number of organizations, and with the wider institutional setting. It is a community-level problem 
of development. The combination of these two aspects renders traditional concepts of leadership in many ways inapplicable.

Turbulent situations are characterized by a high rate of change, uncertainty, and complexity in relationships. This seriously challenges the adaptive capacities of organizations (Emery \& Trist, 1965). The dynamic and uncertain quality of a turbulent environment reshapes the actors' field of possibilities. Recognizing the new field of possibilities, powerful actors compete or collude to construct the new "rules of the game" by attempting new constructions of the situation which would further their objectives (Weick, 1979). In turbulent situations, such novel enactments, as opposed to the routine enactments that support the status quo, become more likely because events are more open to interpretation and manipulation. An actor enacts in a turbulent environment by selecting certain streams of information guided by judgments of value (Weick, 1979; Vickers, 1968).

In the transition from placid to turbulent conditions, managers need to shift their ways of thinking, deciding, and acting. For example, routine operating environments require more proactive and creative management, and wider "contextual" environments require more concerted action (Emery \& Trist, 1965). In addition, functional relationships among a system's actors, and between the system and its environments, often need to be radically transformed.

Yet, managers often stick to the knitting long after the wool is gone. The traditional ways of doing things get reinforced by institutionalized thought structures and fear of the unknown. There is often a need for someone to provide a stimulus, a direction, a vision for the needed changes. This provides opportunities for leaders to intervene with novel enactments to shape the shared field of possibilities and to manage the meanings of events as they unfold (Smircich \& Stubbart, 1985; Smircich \& Morgan, 1982). Development deals with the capacity and motivation of actors in a system to set and achieve objectives (Ackoff, 1974). While a huge body of literature has grown on the subject of organizational development, the nature of community development remains poorly understood. In this article, "community development" means the capacity and motivation of a diverse group of organizational actors to achieve shared objectives (Smith, 1989; Selsky, 1991).

How does this process work? Certain individuals tend to emerge as leaders around certain community issues by implicit consensus (Laumann, Galaskiewicz, \& Marsden, 1978) through the informal networks of actors interested in the issue (Perrucci \& Pilisuk, 1970). These interorganizational networks around an issue comprise an issue domain (Selsky, 1993; Trist, 1983). The leaders then undertake to mobilize resources and capacity for action in the network to address the issue.

We view community development as a type of social change. Social change settings are by nature underorganized (Brown, 1986). Like "shared power problems" of public leadership, often no one is in charge (Bryson \& Crosby, 1992). In institutionalized issue domains such as higher education or health care, dominant actors and groups (doctors, professors) structure the domain around roles, events, and rituals that reinforce their status and position. These established institutional structures and norms denigratc minority interests in the domain, creating disaffected or disadvantaged groups such as poor people or community-based nonprofit organizations. The interests and problems of these groups comprise arenas for social change (Selsky, 1991). 
Achieving social change in an issue domain means rejecting the conventional and enacting alternatives. Such alternatives are poorly understood because research into interventions outside organizations and their hierarchical frameworks is sparse (Brown, 1986; McCann, 1983). Leaders create social change - that is, mitigate community problems when they guide novel enactments in directions that serve the interests of the disadvantaged in a domain. Novel enactments involve breaking the frames of conventional ways of doing things and instilling in community members a capability for questioning established practices. Consistent with the concept of organizational learning, certain individuals such as CEs may serve as learning agents for their community when the capacity for questioning norms and practices becomes embedded in that community (Argyris \& Schon, 1978).

In issue domains where the collective capacity for action is weak, novel enactments may take the form of collaborative endeavors, such as unexpected alliances among diverse organizations. These often have a greater chance than autonomous actions by single organizations of mitigating the problems of disaffected groups of organizations (Emery \& Trist, 1965; Gray, 1989; Selsky, 1991). In the nonprofit sector, a common dilemma for leaders is how to manage the organization while serving broader interests in the community. While this dilemma affects leaders of all organizations that need to satisfy a customer or client market, it is especially intense for nonprofit leaders because of their charitable mission and stewardship of public and private funds. At times, this causes a deep conflict in competing for resources against other nonprofits offering similar services and serving similar constituencies. In addition, the pressures of fundraising and responding to the changing priorities and requirements of funders may distract the leader from the organizational mission and project priorities.

This situation has intensified since the shift to turbulent conditions in the early 1980s. Many nonprofit organizations have fallen away under the pressure, while others carry on desperately on a funding treadmill. Adopting the institutionally expected mindset of a shrinking pie and "doing more with less" often brings out in a nonprofit leader the instinct to survive by seeking competitive advantage.

Community entrepreneurs can help nonprofit managers reframe this mindset through novel enactments of collaboration, as an opportunity to make the pie bigger. For example, public-private partnerships have grown significantly in the past decade to address intractable social problems (Brown, 1986). Community entrepreneurs, working in or with nonprofit development corporations, can serve to integrate the requirements of the players in these partnerships (Bowman, 1987), that is, to "package the deal."

\section{COMMUNITY ENTREPRENEURSHIP: MULTIFRAME, PROACTIVE, AND REFLECTIVE LEADERSHIP}

Can traditional leadership concepts help us to understand and cope with collective action problems in community-based issue domains under conditions of turbulence? A survey of the literature on organizational leadership quickly reveals how much of it is based on four interlocking assumptions:

- Stable, hierarchical structures and unitary normative patterns. Most conventional leadership research is oriented toward the single, "focal" 
organization. An efficient hierarchy of relationships defines and supports the leadership role, such that power resides at the top of the hierarchy and decisions are enacted within predictable normative patterns. These assumptions reflect the institutional context within which most leadership research has been conducted. Institutional structures in modern Western societies tend to be built on values of autonomous, internally consensual action and competitive advantage against other institutional structures.

- Ability to control the environment, including the internal symbolic environment. Defending the organization against encroachments and controlling the environment from the top are seen as prime functions of leadership. These may be accomplished through structural, human-resource, political, and/or symbolic means (Bolman \& Deal, 1991). Recently, the literature on visionary or transforming leadership has added that leaders play a powerful role by framing and reframing situations for others (Bennis \& Nanus, 1985; Bolman \& Deal, 1991) and by managing enactments (Smircich \& Morgan, 1982). Vision deals with the "shared picture of the future we seek to create" (Senge, 1990, p. 9). It often goes unacknowledged that the shared picture is often that of the leader him/herself.

- Individual, heroic, entrepreneurial action. The leadership literature emphasizes personal strength of will, capacity for vision, ability to compete strategically, managing innovation, managing diverse linkages with the organization's environment, and other entrepreneurial qualities (Ansoff, Declerck, \& Hayes, 1976; Pryde, 1981; Bennis \& Nanus, 1985; Drucker, 1985). The heroism and presumed authority implicit in much conventional leadership theory assumes that other organizational participants are powerless, unskilled, and dispirited and need to be either rescued or manipulated by a powerful figure (Senge, 1990; Gemmill \& Oakley, 1992). Leaders acting in elite, dominant, heroic roles reinforce existing institutional structures and tend to disempower other organizational members (Gemmill \& Oakley, 1992).

- Narrow situational contingencies. Bolman \& Deal's (1991) aphorism, that "situations make leaders happen and leaders make situations happen" (p. 448), captures the dominant perspective on leadership that has held sway for over twenty years. We are sympathetic with institutional perspectives which suggest a reframing of the leadership concept away from contingency approaches. Contingency theories do not acknowledge the extent to which leadership practice is normatively cmbedded in broad cultural patterns and institutional belief systems (Biggart \& Hamilton, 1987). This is especially salient in social change settings, where emergent community networks meet up against institutionalized power structures.

Thus, the leadership requirements for managing in complex issue domains have been overshadowed by an emphasis on intraorganizational leadership. The assumptions underlying the conventional leadership literature make many theories and approaches largely inapplicable to social change settings. Community contexts for exercising leadership are substantially different from traditional organizational settings. Participants are diverse, inclusive visions do not exist, decision-making processes are not agreed, and intervenors cannot assume credibility with indigenous actors (see Brown, 1986, pp. 300-306; Gray, 1989). 
In contrast to traditional leaders, how do community entrepreneurs practice their distinctive kind of leadership? Curiously, little attention has been paid to the personal dimension of leadership in the interorganizational literature. The usual foci are the bridging or mediating structure (Trist, 1983; Brown, 1991) and the structural requirements for social problcm-solving (McCann, 1983; Gray, 1989), not the individuals who lead, coordinate, convene, or facilitate them. For instance, Cummings' (1984) review of the literature on transorganizational leadership reads as if the leaders were organizations, not individuals.

Many research reports that take a largely structural approach include descriptive or prescriptive lists of skills and qualities needed by effective change agents in interorganizational settings (see Gray, 1985, 1989; Selsky, 1991; Brown, 1986; Sink, 1991; Waddock \& Post, 1992; Sarason \& Lorentz, 1979; Friend, Power, \& Yewlett 1974). Westley's (1991) review of studies of successful visionary leaders in social change settings is typical. She found that:

characteristically, such leaders exhibit the ability to both perceive and manipulate structure, to directly interact with groups and sentiments at the bottom of the organizational pyramid, and to have the ability to articulate and integrate, in powerfully symbolic form, the various concerns of stakeholders (p. 1015).

Yet, there has been virtually no research focusing on the subjective experience of community leaders in practicing their craft. This is an unfortunate gap, because how a leader in a new or amorphous issue domain enacts his/her role is critical for setting tone, culture and direction.

Our own summary of needed skills and qualities of community entrepreneurs yields the following:

- Multiframe perspectives. CEs deal with a complex and diverse range of issues and stakeholders (Gray \& Hay, 1986; Brown, 1986). Different images of a complex problem routinely emerge when diverse stakeholders interact. CEs play a key role in articulating the diversity of interests, and in synthesizing a "common understanding"(Gray, 1989). CFs are often involved in reframing, but not obliterating, partisan images of the situation. CEs help foster change in established institutional structures and norms by articulating new action possibilities and novel enactments, based on new interpretations of the patterns of action (Kanter, 1983, p. 279). CEs are skilled in reframing the ambiguity in a turbulent situation and in creating a common understanding as the basis for collective action choices (Gray, 1989, p. 5).

Forging a common understanding often involves reframing the conventional value of competitive advantage. CEs seeking to serve the interests of the disadvantaged need to construct win-win solutions based on "collaborative advantage"1 because powerful actors in the domain will not willingly relinquish their power. Seeking collaborative advantage means rejecting the common assumption that there are inherent competitive threats and opportunities in an objective environment (Smircich \& Stubbart, 1985). CEs favor partnerships, alliances, and deals that can mobilize collective capacity in an issue domain. 
- Proactiveness. Actors' interests become manifested through their commitments of resources (Smith, 1989). CEs are skilled in appreciating actors' interests and in identifying the resources that actors need to contribute or parlay towards achieving their shared objectives. CEs broker commitments of resources into networks of commitments to address the issue domain (Smith, 1989). CEs manage events by activating networks of commitments in a game of strategic action with other actors pursuing their own objectives. "Systems of events" consist of events which become connected through the actions of different actors into tightly coupled, recurring, and organized groupings of events (Smith, 1989). The collective outcome of attempts to build and activate networks of commitments through managed systems of events is manifested as a certain pattern of resource mobilization in the issue domain.

Like other types of leader, community entrepreneurs usually do not exercise their skills directly. Paradoxically, they are often in peripheral roles (Burns, 1978), leveraging influence in the community from their small organizational base, using networks rather than formal channels (Trist, 1983), and exercising political skills (Friend, Power, \& Yewlett, 1974). Their management of meaning and commitments is not directive either; CEs help others make their own meaning by working in the background (Smircich \& Stubbart, 1985). Leaders are expected to "deviate, to innovate, and to mediate between the claims of their group and those of others" (Burns, cited in Bryson \& Crosby, 1992, p. 51).

- Reflectiveness. Effective community entrepreneurs continually reflect on their evolving situations. Reflectiveness consists of a practitioner "conversing" with a situation in a dialectic process in which a "unique and uncertain situation comes to be understood through the attempt to change it, and changed through the attempt to understand it" (Schon, 1983, p. 132). Thus, reflectiveness informs practice by helping leaders critique their own enactments (Smircich \& Stubbart, 1985). Reflective practice involves a willingness to question norms and a capacity to "break frames" and refine the action-oriented mental maps of a situation (Bolman \& Deal, 1991; Argyris \& Schon, 1978; Weisbord, 1987). These qualities are important for community entrepreneurs, whose practice is so bound up in testing limits and expanding possibilities for themselves and others (Smircich \& Stubbart, 1985).

\section{METHOD}

In this article, we use an interpretive method; the data consists of our own enactments as community entrepreneurs and our interpretations of them. Interpretive method (also called social constructive method; see Prasad, 1991) acknowledges personal involvement in producing knowledge and, in fact, requires "immersion in the contexts in which action occurs"(Morgan, 1983, p. 391). The method focuses on the rules people use and follow, the multiple realities people inhabit, the meanings attached to acts, and the reasons for action (Smircich \& Stubbart, 1985; Prasad, 1991). 
Consistent with the enactment perspective, we paid attention to certain streams of information that would further our entrepreneurial goals at either the organizational or community level, preferably both at the same time. We would interpret and act on such "attended-to" information according to certain objectives and principles, as noted below.

The scope of our enactments was in two "games" of strategic action: one as executive directors of small nonprofit organizations and the other as network brokers in overlapping issue domains (Sink, 1991; Trist, 1983; Friend, Power, \& Yewlett, 1974). As noted above, this two-level game distinguishes community entrepreneurship from much of intraorganizational leadership. We fully acknowledge the methodological minefield here. There is no way we can be dispassionate commentators on situations in which we became deeply enmeshed and to which we became passionately committed. However, we believe two factors justify our examination of community entrepreneurship as social science research and not as self-serving autobiography.

First, it is grounded in fieldwork consisting of two independent but loosely linked case studies, each of which was conducted as action research. We continually found ourselves in one of the classic action research dilemmas, caught between the dangers of "going native" and the detached, "observing" social scientist (Clark, 1972). Second, our reflective practice as community entrepreneurs was informed by certain conceptual principles. These included the Tavistock tradition of engagement with large-scale social systems, collective strategy as an active-adaptive response to turbulence, and interactive planning with client systems to create desirable shared futures through design. These principles gave a certain direction, method, and grounding to our change-making enactments. This was important because of the lack of established institutional parameters and socialized norms in each of our settings, which often provide focus for intraorganizational change efforts (Biggart \& Hamilton, 1987).

As is characteristic of social change as well as action research settings, the line between intervention and research was indistinct in each of the two cases under study for this article. We believe a reflective frame of reference is critical in such situations because the intervenor becomes the experiment thorough his/her enactments. The values, competencies, perspectives, and modes of inquiry that an intervenor brings to a situation profoundly influence the quality and effectiveness of the intervention. Consequently, it is important to focus on the individuals who adopt leadership roles in social change settings, on the principles that buttress their enactments, and on the quality of their reflectiveness in their practice. Interpretive method is especially well suited for these functions for it "collapses all boundaries between actors, organizations, and environments" (Prasad, 1991, p. 341).

\section{TWO ENTREPRENEURIAL ORGANIZATIONS AND THEIR COMMUNITY SETTINGS}

The two case studies documented in this research were issue domains concerned with community development in Philadelphia's nonprofit sector during the late 1980s, with all the attendant turbulence previously described.

Adversarial roles and competition for funding created dysfunctional patterns of fragmentation and uncertainty. For example, some local nonprofits in the energy field 
pressured state and municipal regulatory agencies to curb the authority of utility companies to shut off heating to delinquent customers during the winter. Unexpectedly, this led to a larger number of payment delinquencies and higher bills for paying customers. In addition, those same energy-related nonprofits were pitted against each other by adroit utility companies offering them contracts for home weatherization services on a competitive bid basis.

The shift in the environment to a more turbulent texture was not immediately apparent to many managers of small nonprofits. Perhaps because we (the authors) were somewhat removed from the mainstream, we recognized that new collaborative strategies for joint fundraising and institution-building were needed. Yet, traditional models of organizational leadership gave little clue about how to make this happen. We had to construct our own approaches. It was our belief that small nonprofits, including our own organizations, needed to begin to create, and not just adapt to, events and trends to fulfill their objectives. Moreover, we discarded the strategy for competitive advantage as being ineffective, if not ultimately counterproductive in the management of our own organizations. We chose instead to adopt the strategy for collaborative advantage. Below we outline the two settings, detail two typical examples of this strategy, and illustrate the implications for our leadership practice at the community level.

\section{Community Energy Development Corporation (CEDC)}

Smith, one of the authors, founded Community Energy Development Corporation (CEDC) in 1981 and served as its executive director for five years through the research period. CEDC was a community-based, nonprofit enterprise that brokered and marketed a variety of energy-related products and services in both the for-profit and nonprofit sectors in Philadelphia. Its efforts focused on an economically depressed urban neighborhood of 100,000 people, where the agency was located. CEDC's funding strategy was to generate most of its operating revenue from program fees, topped up with occasional supporting grants, and to seek project-specific seed grants.

Smith saw an opportunity for creating a community enterprise in the tremendous costs to the community of wasted energy. By reframing wasted energy as a resource for capital and job retention in the community, he articulated shared interests of a community of diverse stakeholders. These included landlords, tenants, homeowners, utility companies, unemployed residents, small businesses, city taxpayers, and an array of other public and private sector interests (Smith, 1989). His specific objectives included reducing energy consumption in buildings; lowering operating costs and pressures on rent increases in apartment buildings; providing job training and creating jobs for unskilled community residents; increasing public awareness of self-help strategies to reduce their energy requirements while improving comfort; and creating a variety of financing, marketing, and service delivery mechanisms to stimulate private-sector investment in energy conservation. In working with these actors and their interests, Smith sought to create systems of events with "win-win-win" benefits to three parties, namely CEDC itself, the partners it was engaging with in any particular project, and the geographic community (Smith, 1989). 
Over a five-year period, Smith was able to translate this personal vision into complex networks of commitments and systems of events. Smith leveraged CEDC's initial foundation grant of $\$ 25,000$ into a variety of tangible results, including over 60 community residents trained in weatherization skills, over 10,000 low-income housing units weatherized, over one million gallons of discounted oil delivered per year, and over $\$ 4$ million in private sector investment stimulated.

\section{Delaware Valley Council of Agencies (DVCA)}

Selsky, the other author, was a founding board member of the Delaware Valley Council of Agencies (DVCA) and its executive director for part of the research period. DVCA was a nonprofit membership association composed of 148 small nonprofit organizations, mainly social service agencies and community-based organizations in a five-county area. Its purpose was to develop the capacity of the region's nonprofit sector to manage its environments through various collaborative activities. DVCA's leadership group consisted of staff, active board members, and the executive directors of several member agencies. That group established a three-pronged program strategy to mobilize resources:

- Cost-saving programs included a member-to-member exchange network and a resource bank of donated equipment and furniture; and contract-purchasing arrangements in office supplies, fuel oil (provided by CEDC), and insurance services (health, dental, and retirement). Members who used these programs saved thousands of dollars by foregoing the purchase of equipment and supplies, and by purchasing goods at discount prices.

- Education programs included training programs, conferences, newsletters, and publicity events. These were designed to facilitate interactions among members and to communicate values of "nonprofit-ness," exchange and sharing of resources, and cooperation with fellow members. These linkages increased the flows of information within the association, which were important in identifying new projects and sources of resources in the community.

- Advocacy programs included state sales tax regulations for nonprofits, United Way donor-option policies, and liability insurance problems of nonprofits. In this area, DVCA identified issues of importance to all nonprofit organizations in the region.

The goal of the program strategy was to generate revenues from cost-saving programs and membership dues. In this way, DVCA could become less dependent on external funding used to cover operational expenses. It could also sponsor initiatives in nonprofit advocacy and system change with greater independence. To accomplish this, Selsky and others needed to reframe the context within which many local nonprofit managers made decisions and took action. They promoted a consciousness of nonprofit-ness, which previously had not existed, and articulated common cause and shared interests. They tried, with some success, to brcak those managers out of insular decision-making loops and give them a sense of collective power. 


\section{INTERCONNECTIONS OF THE TWO CASES}

Each of these organizations had an organizational orientation and a community orientation. Each was a new, small, nonprofit organization, precariously positioned in turbulent funding, client, and institutional environments. Each had entrepreneurial missions and objectives, and the leaders of each sought to use collaborative strategies to build capacity in its domain for social change.

At the community level, DVCA initiated and coordinated collaborative activities among its member organizations, while it itself functioned as a vehicle, along with other associations, for building capacity at the sector level. CEDC initiated and coordinated collaborative programs and partnerships which enabled local residents, managers of apartment buildings, and leaders of nonprofit organizations to gain more control over their energy expenditures.

The two organizations were closely connected in several specific ways. As a member agency of DVCA, CEDC participated actively in and helped to shape DVCA policies and strategies. The two executive directors (the authors) sought funding from several of the same local foundations, and they established several contractual agreements between their two organizations, as described below. In addition, Selsky and Smith were both writing doctoral dissertations in the same graduate department, they both used their work settings as field sites, and they enjoyed overlapping personal and professional networks.

Two critical incidents illustrate how these two organizations intersected and how the authors used systems of events and novel enactments to mobilize commitments and resources.

\section{First Example of Systems of Events}

The first example begins with the purchase of article supplies. Like many small nonprofits, CEDC used a moderate amount of copying paper and had always paid top dollar for it. One of Smith's motives in joining DVCA was to reduce CEDC's copying paper bill. CEDC purchased paper through DVCA's vendor contract for about one year, then discovered a less expensive vendor. CEDC stopped buying paper through DVCA, though it retained its membership and participated in other programs. Membership in DVCA helped Smith to expand his field of possibilities regarding managing CEDC's resources more effectively. This was consistent with Selsky's strategy for DVCA to help improve the capacity of local nonprofits to manage their affairs more proactively. Nonetheless, CEDC's shift to an outside vendor compromised DVCA's entrepreneurial interests because DVCA lost a regular customer.

Several months later, the director of CEDC's heating oil cooperative program approached Selsky with a proposal to market the co-op to other Council members. Selsky was very interested, and he and the program director quickly negotiated the terms of an agreement. This program continued for three years. During the first year of the program, six other local nonprofits with missions in the energy sector joined DVC $\Lambda$, and they became very active members. In the following year, Selsky initiated discussions with representatives of all seven energy-sector member agencies. Selsky packaged the resulting agreements into a new program called "Energy Products and Services." During the following year, more creative offerings were added, and 
refinements were made in some technical terms based on the previous year's experience.

From the perspective of its energy-sector members, DVCA not only represented an investment in managing their resources more efficiently; it was also seen as valuable in contributing to the overall health of the nonprofit energy sector. Smith perceived DVCA as ultimately strengthening the field of possibilities for all energy-related nonprofit organizations in the region. From DVCA's perspective, the affiliation of the seven energy-sector organizations contributed to its (DVCA's) clout as a new association seeking legitimacy in the nonprofit community.

Member participation in DVCA's programs was voluntary. DVCA expected a certain proportion of its membership to participate in any particular program, to justify to vendors the promised volume of purchasing that would be channeled their way. Selsky's initiative to package all the energy products and service offerings of members and to promote them to other members at special rates was a result of the initial discussions with CEDC about heating oil. Those discussions fortified Selsky's belief that DVCA could play an important role as a sector-wide catalyst for new programs and new relationships.

This example shows how a simple exchange relationship (that is, the discounted purchase of copying paper as a membership benefit) evolved into a complex, multilateral system of events and new strategic relationships (that is, joint marketing of energy products and services). The CEs activated a network of commitments to achieve collaborative advantage for all participants.

\section{Second Example of Systems of Events}

The second example concerns the establishment in Philadelphia of a branch office of the Joint Purchasing Corporation (JPC), a New York-based nonprofit organization. JPC's mission was to aggregate the purchasing power of large nonprofits, especially hospitals and colleges, in vendor contracting arrangements. JPC's arrival in Philadelphia represented a competitive threat both to CEDC and DVCA. JPC intended to establish a heating oil cooperative, in direct competition with CEDC's discount oil program. For its part, DVCA was expanding its range of commonly needed items that it planned to broker on behalf of its members. DVCA was lower on the learning curve than JPC and was concerned that the newcomer would steal potential members with the larger discounts it (JPC) could offer.

Soon after his arrival in Philadelphia in mid-1985, JPC's regional director contacted Selsky at DVCA for general discussions regarding market segments and product offerings. Selsky quickly informed his board of his concern over a possible competitive threat to DVCA's future program plans. Over the next several months, Selsky and the JPC director negotiated a detailed, formal memorandum of agreement that formalized an exchange of memberships, specified the technical conditions under which each organization's benefits would accrue to the other's member organizations, and established competitive boundaries between the two associations.

Having concluded the agreement with JPC, Selsky was then willing to introduce Smith to the regional director. The three held several uneasy meetings regarding cooperative arrangements for purchasing heating oil by local nonprofit organizations. 
Smith proposed a joint venture arrangement with JPC, and later a three-way venture that also included CEDC's oil supplier. The proposal was to offer firm fixed-price contracts, hedged against the oil futures market, to DVCA members. The regional director was interested but, unfortunately, JPC's central office in New York was not. JPC and CEDC went their separate ways, although both were now members of DVC $\Lambda$.

Selsky's intervention to bring Smith and the JPC director together for discussions of mutual interest (and potential threat!) enhanced each party's strategic capabilities by constructing a shared environment for action. The unknown (e.g., who is our competition?) became the more manageable known (they are our competitors, so how can we differentiate our market segments?). Each party was driven by his respective organizational commitments to explore ways to increase market share. It was implicitly understood by all three leaders that this be attempted first by negotiating with the others. In addition, Smith, as a member of DVCA, was committed to engage in discussions suggested by his DVCA colleague Selsky.

From the discussions, all three parties gained a better appreciation of the environments they were operating in, as well as learning about the other parties. Initial threat and defensiveness yielded to strategic negotiation and learning. For example, Smith learned that JPC's market niche was simply high volume and low price, and that their oil distribution service was only part of a large range of products aimed at the nonprofit institutional market. Smith's response was to differentiate CEDC's oil product by hedging on the futures market, thus buffering its customers against the swings of the spot market through firm fixed pricing. CEDC also differentiated its structure by creating a for-profit subsidiary dedicated exclusively to bulk oil vending. Selsky learned about DVCA's capacity and limitations for brokering commitments through the events that it constructed and managed.

On first reading of this example, it appears that Selsky's frame was community focused and Smith's was organizationally focused. That is, from Selsky's perspective, both CEDC and JPC were members of the Council, and he wanted to foster more resource exchange for the ultimate benefit of his entire membership. From Smith's perspective, he wanted to defend his market niche against encroachment from one of the "big boys" and to learn how to do so more effectively. All three parties achieved their goals, since the range of opportunities increased for each as a result of Selsky's initial intervention and the system of events that flowed from it.

A deeper appreciation of this example suggests that Selsky, with an immediate need to sustain DVCA as a small nonprofit organization, had interests in offering a new benefit to his members (thereby increasing the value of DVCA membership) and in obtaining commissions that might accrue from his members' purchases of JPC or CEDC products. Smith's broader interests were to learn more about the operating environment he shared with JPC (and to some extent with DVCA) and to explore the possibility of a value-added service that would benefit all parties. Thus, both organizations and their domains benefited from the multiframe perspectives of their leaders. Collaborative advantage derived from the actors' abilities to exploit the multiframe perspective.

There were countless other examples of reframing, managing events, and mobilizing commitments and resources in each setting. It is difficult to convey the rich texture of our working lives during this period. Reframing was a continual process in our daily work. Ideas were hatched, schemes were plotted, deals were struck, programs were 
packaged, resources were brokered, funds were obtained or withdrawn, committees and task forces came and went, staff morale rose and fell in a kaleidoscope of activity where each event was calculated to serve multiple goals, interests, and values.

In summary, the practice of community entrepreneurship enabled collective capacity to develop in each domain. Smith's leadership strategy with CEDC was to create strategic alliances with a variety of public and private stakeholders in the energy community - who had shared interests at the organizational level. Selsky's leadership strategy with DVCA was to create strategic alliances among stakeholders in the nonprofit sector-who shared interests by virtue of their resource constraints and charitable mission.

\section{DISCUSSION}

Leaders of small organizations often feel powerless in the face of great institutional forces over which they have little control. Both DVCA and CEDC each had relatively modest annual operating budgets, yet their executive directors each brokered millions of dollars in resources for their constituencies. How did they manage to do so? In our leadership practice, each of us played an organizational and a community "game." We linked these two orientations continually by enacting events that would serve objectives in both games. The power of community entrepreneurship comes not from keeping a small nonprofit organization going in a turbulent environment, virtuous as that may be. Its power lies the ability to influence the course of events in an issue domain from a seemingly peripheral and resource-scarce position.

This influence derived from our substantive strategy as well as our process strategy. The substantive strategy dealt with community development. It involved innumerable mundane quandaries, such as how to get the insurance agent to agree to include agencies of less than five employees in the dental plan. These mundane issues were tied together by a vision of developing collective capacity for goal setting.

For us, the community development process resided in the interplay of activating commitments and mobilizing resources. We used commitments in both examples to mobilize resources. For instance, in the first example, members' commitments to purchase commodities and services through DVCA later led some members, such as the seven energy-sector agencies, to explore new strategic relationships with each other and with DVCA.

Conversely, the first example also shows how the mobilization of resources can provoke commitments. For example, participating in a bulk purchase program for copying paper can symbolize administrative costs for one member, commitment to community values for another member, or program revenues for the DVCA leader. By tapping into these perspectives, community entrepreneurs use resources to help people declare their interests through tangible commitments. When people see the possibility of achieving their goals by mobilizing additional resources through collective action, it helps people to reframe and define their commitments to collective action.

The examples also show that the coupling of commitment and action is uneven. To some extent, this constrains resource mobilization. For example, Selsky, as head of a new membership organization, was striving for DVCA to be both entrepreneurial in the community and also responsive to its own organizational goals. DVCA's 
members'avowed commitments to participate in certain bulk purchase programs helped him to decide which organizational commitments at which levels to make to vendors in developing different programs. Selsky encountered problems with maintaining credibility with disappointed vendors when some members failed to honor their commitments with purchases at the avowed levels. It is critical for CEs to appreciate that commitments and action build incrementally and unevenly (Quinn, 1977).

An important developmental tension in building community capacity lies at the heart of this uncertainty about commitment and is illustrated in the first example. What inspired an organization like CEDC to become and remain a member of DVCA differed from what induced it to participate in any of DVCA's programs. The dynamics that drive affiliation (in this case, membership in DVCA) and participation differ (Selsky, 1991). Affiliation involves institutional issues of ownership and legitimacy. It depends on and implicates commitments. Participation involves instrumental issues of exchange and negotiation. A commitment to purchase copy paper, for example, is usually tied to well defined instrumental conditions-for example, that the product is still needed, or that it cannot be obtained elsewhere at a lesser price. These conditions can vary over time, especially in turbulent settings, and the community entrepreneur needs to stay on top of changes in his "market" to effectively manage the shifting network of commitments. As noted above, existing and anticipated resources can determine how commitments become translated into individual actions and collective events.

The process strategy consisted of three elements: a multiframe perspective, a proactive management of events, and reflectiveness in our practice. The two cases illustrate that community entrepreneurs try to actively reframe the widely divergent images of a situation in a way that captures the attention of other stakeholders around ccrtain meanings (e.g., values, policies, events) (Gray, 1989). They do so by constructing events that implicate commitments of resources. But the examples show how interactive reframing can be. For example Smith was continually seeking win-win solutions to problems in the energy community that would also satisfy CEDC's organizational goals. His efforts provoked certain kinds of responses in other stakeholders - to play along with his attempts, to thwart them, or to try to manage his commitments. In turn, these responses would help him to understand better how to enact events and mobilize commitments in that community. Responding to this interactive process improves the probability of successful community development.

Community entrepreneurs view naturally occurring events as part of an unfolding process in an issue domain that can be influenced but not controlled. In the second example, the unexpected arrival of JPC in Philadelphia provoked responses by both DVCA and CEDC as they scrambled to turn a potential threat to their advantage. The ambiguity of this event in its turbulent context allowed the different actors to respond to the event according to their own interests and perspectives (Gray, 1989; Rubin, 1986). To the extent that CEs can capture spontaneous events and harness them to serve their objectives, then those events help to (re)shape the field of possibilities for subsequent action by leaders and other actors.

The cases and examples point out the importance of learning about a situation through novel enactments. Enacting events reveals a system's structure and patterns of relationships, not as an abstract concept but as perceived and enacted reality (Crozier \& Friedberg, 1980; Smith, 1989). Acting on an ambiguous situation helps a leader to 
get a clearer appreciation of how the situation is structured (Weick, 1979) and how it may be restructured to provide more benefits.

We practiced reflectiveness in our enactments through organizational retreats, meetings among community leaders, and most importantly, by continuously involving various stakeholders in a dialogue about shared goals. These goals became the foundation for developing program-specific systems of events. Having obtained agreement among interested stakeholders on an envisioned system of events, we were then able to engage them in designing their future involvement concerning the program. This occurred in a retrospective-prospective process of tracing back from the desired future to the present. This would clarify what resources would be needed, what commitments would need to be activated, and what events might need to be enacted.

An experimental attitude is vital for a community entrepreneur. We could rarely predict how a particular enactment would play out, but we were willing to learn from experimenting and occasionally failing. Through reflective practice, we built up a "repertoire of examples, images, understandings, and actions" (Schon, 1983, p. 138) which enabled us to engage in reflective conversations with diverse actors to better understand our collective situation.

CEs synthesize diverse interests by reframing situations in the direction of collaborative advantage. In this activity, CEs seek to empower and not to control others. While on the one hand, each of us had very definite interests to ply and goals to achieve, on the other hand, neither of us was interested in amassing power. We rejected traditional assumptions about the heroism, control, and competitiveness of leaders and the outcomes that often flow from them. In resource-scarce communities, those outcomes tend to favor the well off. Instead, we sought to broaden community entrepreneurship and develop learning capability in our respective communities, working in dynamic collaboration with others (Gemmill \& Oakley, 1992).

It is important to recall that we were both working in the nonprofit sector, with economically disadvantaged people (Smith) and community-based organizations (Selsky). Undoubtedly, this is the most underdeveloped sector in the U.S. economy. The agenda for social change is to break the frame that keeps the disadvantagedwhether individuals or organizations - in powerless positions. Appreciating that institutional structures and norms are socially constructed can liberate us to conceive of manipulating them to suit our own interests. Dominant institutions cannot claim to hold a monopoly on a community's or a society's "real" or legitimate goals or interests once they are recognized as constructed from traditional power bases. This is the power of novel enactments for the disadvantaged.

Community entrepreneurs are limited in their ability to influence complex, illstructured, and politicized domains. As Gray and Hay (1986) point out, the political dynamics common in interorganizational collaborations often constrain "the microlevel interventions [from] ... producing the desired macrolevel consequences" (p. 104). Nevertheless, power appears to accrue to community leaders through entrepreneurial and not traditional managerial behavior. The entrepreneurial practices discussed in this article enable leaders of small organizations to exercise more power in influencing their operating environments than the size or status of their organizations would suggest. 


\section{CONCLUSION}

Although it is difficult to generalize from interpretive research accounts, we feel it is important to broaden the discourse of this article to understand how and where community entrepreneurship may be applicable. We do so in four directions: the settings and their issues and problems; the examples; the organizations; and the strategy of community entrepreneurship.

In our work, each of us was dealing with a publicly "opaque" problem. In one case, the problem was the lack of collective capacity in the regional nonprofit sector, and in the other, the issue of concern was energy inefficiency in low-income neighborhoods. We were not dealing with big, transparent issues like drug abuse or homelessness, which become social policy fads or topical community issues and are thereby able to command large amounts of resources for a time. It is important, however, to understand the less visible problems, because they texture the life experiences of disadvantaged people and community-based organizations and because they are the wellspring of future fads and issues.

The two examples may seem to be of little consequence. Indeed, much of organizational and community life consists of rather mundane events whose potentials are difficult to discern. Our two examples represent typical systems of events in issue domains that occurred in the real world; symbolized initial commitments that broadened over time, partly due to our efforts and partly to those of others; implicated initial resources, or commitments for them, which escalated over time; and led towards certain tangible outcomes and away from others. Understanding these sorts of vignettes as systems of events and commitments may help us to improve how our organizations and communities operate and develop.

Similarly, CEDC and DVCA can be viewed as exemplars of the numerous small nonprofit organizations as well as nongovernmental organizations and other peripheral groupings in social change arenas trying to survive in a turbulent world through entrepreneurial leadership. They are subject to embedding conditions, such as national social policies and trends in sector funding, as well as enormous pressures for conformity, efficiency, and rationalization from the "mainstream." Nevertheless, they also are able to retain some measure of creativity, autonomy, and humanity; and they are able to exert some positive influence over the course of events in selected issue domains.

We conclude with a reflection on our key construct. We believe community entrepreneurship is a more powerful concept for examining complex social change processes in a community than conventional treatments of leadership. It suggests a more pluralist approach to social change, in two senses. First, our approach strives to acknowledge and build upon the natural differences in interests in a complex system, while at the same time striving to build a unifying framework of understanding and values to cope with turbulent forces affecting all actors. Second, our approach acknowledges the diversity of actors operating with different world views, organizational roles, power positions, and levels of involvement in a social change setting.

Thus, community entrepreneurship as a leadership strategy is a method of inquiry and a method of intervention appropriate in social change settings. As a method of 
inquiry, community entrepreneurship may help to provide critical knowledge by examining active engagements with complex social systems. As a method of intervention, community entrepreneurship may provide better guidance to change agents attempting to mobilize commitments, build systems of events, and develop collective capacities for action in issue domains.

We believe that this approach strengthens the constructive diversity and pluralistic democracy that enables our communities to adapt and thrive in turbulent environments. We hope our experiences and reflections will help other social change leaders in practicing community entrepreneurship.

\section{NOTE}

1. Quoted from a personal communication from Oguz Baburoglu on collaborative strategy, September 1993.

\section{REFERENCES}

Ack off, R. (1974). Redesigning the future. New York: Wiley.

Ansoff, I., Declerck, R., \& Hayes, R. (1976). From strategic planning to strategic management. In I. Ansoff (Ed.), From strategic planning to strategic management (pp. 39-78). New York: Wiley.

Argyris, C., \& Schon, D. (1978). Organizational learning: A theory of action perspective. Reading, MA: Addison-Wesley.

Bennis, W., \& Nanus, B. 1985). Leaders. New York: Harper \& Row.

Biggart, N., \& Hamilton, G. (1987). An institutional theory of leadership. Journal of Applied Behavioral Science, 23(4), 429-441

Bolman, L., \& Deal, T. (1991). Reframing organizations. San Francisco, CA: Jossey-Bass.

Bowman, A. (1987). Elite organization and the growth machine: The nonprofit development corporation. In G.W. Domhoff \& T. Dye (Eds.), Power elites and organizations. Beverly Hills, CA: Sage.

Brown, L.D. (1986). Power outside organizational paradigms. In S. Srivastva \& Associates (Eds.), Executive power. San Francisco, CA: Jossey-Bass.

Brown, L.D. (1991). Bridging organizations and sustainable development. Human Relations, 44(8), 807-831.

Bryson, J., \& Crosby, B. (1992). Leadership for the common good. San Francisco, CA: JosseyBass.

Burns, J.M. (1978). Leadership. New York: Harper.

Clark, P. (1972). Action research and organizational change. New York: Harper \& Row.

Crozier, M., \& Friedberg, E. (1980). Actors and systems. Chicago: The University of Chicago Press.

Cummings, T. (1984). Transorganizational devclopment. In B. Staw \& T. Cummings (Eds.), Research in Organizational Behavior (Vol. 6, pp. 367-422). Greenwich, CT: JAI Press.

Drucker, P. (1985). Innovation and entrepreneurship. New York: Harper \& Row.

Emery, F., \& Trist, E. (1965). The causal texture of organizational environinents. Hurmun Relations, 18, 21-32.

Friend, J., Power, J., \& Yewlett, C. (1974). Public planning: The intercorporate dimension. London, UK: Tavistock. 
Gemmill, G., \& Oakley, J. (1992). Leadership: An alienating social myth? Human Relations, 45(2), 113-129.

Gray, B. (1985). Conditions facilitating interorganizational collaboration. Human Relations, 38, 911-936.

Gray, B., \& Hay, T. (1986). Political limits to interorganizational consensus and change. Journal of Applied Behavioral Science, 22(2), 95-112.

Gray, B. (1989). Collaborating: Finding common ground for multiparty problems. San Francisco, CA: Jossey-Bass.

Kanter, R. (1983). The change masters. New York: Simon \& Schuster.

Laumann, E., Galaskiewicz, J., \& Marsden, P. (1978). Community structure as interorganizational linkages. Annual Review of Sociology, 4, 455-484.

McCann, J. 1983. Design guidelines for social problem solving interventions. Journal of Applied Behavioral Science, 19(2), 177-192.

Morgan, G. (1983). In research, as in conversation, we meet ourselves. In G. Morgan (Ed.), Beyond method (pp. 405-407). Beverly Hills, CA: Sage.

Perrucci, R., \& Pilisuk, M. (1970). Leaders and ruling elites: The interorganizational bases of community power. American Sociological Review, 35, 1040-1057.

Prasad, P. (1991). Organization building in a yale union. Journal of Applied Behavioral Science, 27(3), 337-355.

Pryde, P. (1981). Human capacity and local development enterprise. In R. Friedman \& W. Schweke (Eds.), Expanding the opportunity to produce: Revitalizing the American economy through new enterprise development (pp. 521-533). Washington, DC: The Corporation for Enterprise Development.

Quinn, J.B. (1977). Strategic goals: Process and politics. Sloan Management Review, (Fall), 2137.

Rubin, M. (1986). Towards a concept of mediated development. Unpublished Ph.D. dissertation, University of Pennsylvania, Philadelphia.

Sarason, S., \& Lorentz, E. (1979). The challenge of the resource exchange network. San Francisco, CA: Jossey Bass.

Schon, D. (1983). The reflective practitioner. New York: Basic Books.

Selsky, J. (1991). Lessons in community development: An activist approach to stimulating interorganizational collaboration. Journal of Applied Behavioral Science, 27(1), 91-115.

Selsky, J. (1993). An exploration of developmental dynamics in maturing nonprofit federations. Working Paper 93/01, Management Department, University of Otago.

Senge, P. (1990). The fifth discipline. New York: Doubleday.

Sink, D. (1991). Transorganizational development in urban policy coalitions. Human Relations, 44(11), 1179-1195.

Smircich, L., \& Morgan, G. (1982). Leadership: The management of meaning. Journal of Applied Behavioral Science, 18(2), 257-273.

Smircich, L., \& Stubbart, C. (1985). Strategy making in an enacted world. Academy of Management Review, 15(4), 724-736.

Smith, A. (1989). Entrepreneurial development of organizational communities: An events-focused planning approach. Unpublished Ph.D. dissertation, University of Pennsylvania, Philadelphia

Trist, E. (1983). Referent organizations and the development of interorganizational domains. Human Relations, 36(3), 269-284.

Vickers, G. (1968). Value systems and social process. London, UK: Penguin.

Waddock, S., \& Post, J. (1992). Social entrepreneurs and catalytic change. Public Administration Review, 5I(5), 393-401. 
Weick, K. (1979). The social psychology of organizing. 2nd edn. Reading, MA: Addison-Wesley. Weisbord, M. (1987). Productive workplaces. San Francisco, CA: Jossey-Bass.

Westley, F. (1991). Bob Geldof and live aid: The affective side of global social innovation. Human Relations, 44(10), 1011-1036. 